\title{
Study of the spectral and power characteristics of In0.2Ga0.8N/GaN superluminescent light emitting diodes by taking into account the piezoelectric polarization fields
}

\author{
Hassan Absalan ( $\nabla$ absalanh@gmail.com ) \\ Urmia University https://orcid.org/0000-0002-1373-2820 \\ Mir Maqsood Golzan \\ Urmia University \\ Nasser Moslehi Milani \\ Islamic Azad University Ahar Branch
}

\section{Research Article}

Keywords: superluminescent light emitting diodes, internal electric fields, piezoelectric field, spectral and power characteristics, rate equations

Posted Date: March 24th, 2021

DOl: https://doi.org/10.21203/rs.3.rs-223965/v1

License: (c) (1) This work is licensed under a Creative Commons Attribution 4.0 International License.

Read Full License

Version of Record: A version of this preprint was published at Optical and Quantum Electronics on July 14th, 2021. See the published version at https://doi.org/10.1007/s11082-021-03025-4. 


\title{
Study of the spectral and power characteristics of $\mathrm{In}_{0.2} \mathrm{Ga}_{0.8} \mathrm{~N} / \mathrm{GaN}$ superluminescent light emitting diodes by taking into account the piezoelectric polarization fields
}

\author{
Hassan Absalan ${ }^{1 *}$. Mir Maqsood Golzan ${ }^{1}$. Nasser Moslehi Milani ${ }^{2}$ \\ ${ }^{1}$ Department of Physics, Faculty of Science, Urmia University, Urmia, Iran \\ ${ }^{2}$ Department of Physics, Ahar Branch, Islamic Azad University, Ahar, Iran
}

\begin{abstract}
In this study, the effects of the piezoelectric polarization field have been investigated on the spectral and power characteristics of $\mathrm{In}_{0.2} \mathrm{Ga}_{0.8} \mathrm{~N} / \mathrm{GaN}$ superluminescent light emitting diodes. The Schrödinger and Poisson equations, the rate equations in the multiple quantum well active region and separate confinement heterostructure layers, and the optical propagating equations have been solved in the presence of the piezoelectric field. The results have been compared with results of the case of without piezoelectric field. According to the results, in the presence of piezoelectric field, the red-shift occurs in the spectra, and the width of spectrum increases. Also, the piezoelectric field decreases the peak intensity of spectrum and modal gain of the device.
\end{abstract}

Keywords superluminescent light emitting diodes . internal electric fields . piezoelectric field . spectral and power characteristics . rate equations

\section{Introduction}

The suitable design of the electronic devices based on InGaN/GaN heterojunctions requires an accurate investigation of the effects of polarization on the quantum well $(\mathrm{QW})$ structures. The performance of devices based on InGaN/GaN can be improved by increasing the information on internal electric fields. The piezoelectric (PZ) polarization is proportional to the strain induced by the lattice mismatch [1]. Furthermore, the spontaneous polarization (SP) is an intrinsic property resulting from the internal cell parameters $c / a$ of the wurtzite materials [2]. In the QW structures, $\mathrm{PZ}$ and SP polarizations are the sources of an internal electric field in the range of $\mathrm{MVcm}^{-1}$ which causes the so-called quantum confined Stark effect (QCSE) [3]. This field can affect the spectral and the power characteristics of the device [4].

\footnotetext{
${ }^{*}$ Corresponding author, E-mail: h.absalan@urmia.ac.ir
} 
A superluminescent light emitting diode (SLD) is an edge emitter semiconductor optical source which contains regions of QWs, barriers, separate confinement heterostructure (SCH) and cladding layers. A SLD is based on a p-n junction that operates in amplified spontaneous emission (ASE) regime when it is forward biased. Also the SLD has low optical feedback, and there is no laser performance on it. A SLD combines the low temporal coherence of light emitting diodes (LEDs) with high spatial coherence of laser diodes (LDs). The key parameters for describing SLDs are output power, optical gain, spectrum bandwidth, coherence length, spectrum modulation, and coherence function. The SLD has been developed as a key element in fiber optic gyroscopes, optical coherence tomography for medical imaging, and fiber-optic communication devices. Other applications include optical fiber sensors, display screens for projectors, optical test instruments, and spectroscopy [5-10].

Most produced SLDs are based on GaAs and InP. In recent years, studies have been conducted on GaN-based SLDs. A high optical power blue-emitting SLD grown on semi-polar bulk GaN substrate was described by C. Shen et al. [11]. Also, A. Kafar et al. have reported InGaN/GaN superluminescent diodes with broadened emission spectra fabricated on surface-shaped bulk GaN (0001) substrates [12]. M. T. Hardy et al. have conducted theoretical studies on the GaN based SLDs [13]. K. Holc et al. have examined the temperature dependence of InGaN-based SLD structures [14]. N. M. Milani et al. have presented a new theoretical model for broadband blue InGaN/GaN SLDs [15]. However, the effects of polarization fields on the output of SLDs have not been considered in any of these studies. Given the importance of polarization in nitride materials, the effect of polarization on SLDs must be taken into account. In this article, we examine the effects of the polarization on the spectral and power characteristics of $\operatorname{In}_{0.2} \mathrm{Ga}_{0.8} \mathrm{~N} / \mathrm{GaN}$ multiple quantum well (MQW) blue SLD via a self-consistent solution of the Schrödinger and Poisson equations, the rate equations in MQW active region and SCH layers, and the optical propagating equations.

\section{Theory}

The polarization in the SLD has the excellent effect on the recombination of carriers. Therefore it is important to have a precise description of the polarization. The PZ coefficients of $\operatorname{In}_{\mathrm{x}} \mathrm{Ga}_{1-\mathrm{x}} \mathrm{N}$ vary linearly with indium mole fraction [16]. In $\operatorname{In}_{\mathrm{x}} \mathrm{Ga}_{1-\mathrm{x}} \mathrm{N} / \mathrm{GaN}$ structure, which is under the influence of biaxial compressive strain, the PZ polarization is in the (0001) direction, therefore the SP and PZ polarizations opposes each other [17]. In this structure, the PZ field is much bigger than the SP polarization, so the total internal field value is close to that of the PZ field. If a material is grown as pseudomorphically on a substrate with different lattice constant, the grown layer is related to $\mathrm{PZ}$ polarization. The $\mathrm{PZ}$ polarization in the grown layer is expressed as follows [1]

$$
P_{P Z}=2 \varepsilon_{x x}\left(e_{31}-e_{33} \frac{c_{13}}{c_{33}}\right)
$$

where $\varepsilon_{x x}$ is the basal strain that defined as, 


$$
\varepsilon_{x x}=\frac{a_{\text {GaN }}-a_{\text {InGaN }}}{a_{I n G a N}}
$$

where $a_{\text {GaN }}$ is the lattice constant of substrate, and $a_{I n G a N}$ is the lattice constant of grown layer. The PZ field is expressed as follows

$$
F=-\frac{P_{P Z}}{\kappa \varepsilon_{0}}
$$

where $\kappa$ and $\varepsilon_{0}$ are the dielectric constant of the semiconductor and vacuum permittivity, respectively. The material parameters of $\operatorname{In}_{0.2} \mathrm{Ga} 0.8 \mathrm{~N}$ are listed in Table 1.

Table 1 Material parameters of $\operatorname{In}_{0.2} \mathrm{Ga}_{0.8} \mathrm{~N}$

\begin{tabular}{lcccc}
\hline \hline Parameter & Symbol & Unit & Value & Refs. \\
\hline Lattice constant at 300K & $a_{\text {InGaN }}$ & $A$ & 3.26 & 18,19 \\
Static dielectric constant & $\kappa$ & $\varepsilon_{0}$ & 11.06 & 19 \\
Band gap energy at 300K & $E_{g}$ & $e V$ & 3.19 & 18 \\
Elastic stiffness constant & $c_{11}$ & $G P a$ & 356.6 & 20 \\
Elastic stiffness constant & $c_{12}$ & $G P a$ & 139.0 & 21 \\
Elastic stiffness constant & $c_{13}$ & $G P a$ & 103.2 & 22 \\
Elastic stiffness constant & $c_{33}$ & $G P a$ & 210.4 & 22 \\
Piezoelectric constant & $e_{31}$ & $C m^{-2}$ & -0.34 & 23 \\
Piezoelectric constant & $e_{33}$ & $C m^{-2}$ & 0.54 & 19,23 \\
Spontaneous polarization & $P^{S P}$ & $\mathrm{Cm}^{-2}$ & -0.041 & 18 \\
Hydrostatic deformation potential & $D$ & $e V$ & -6.76 & 24
\end{tabular}

In order to design an appropriate SLD, it is necessary to have information about the band structure of the active region as well as the effects of the internal electric field on it. This is done by solving the Schrödinger and Poisson equations separately for conduction and valence bands based on effective mass approximation under an electric field. The polarization can alter the optical and electrical characteristics of the structure. Hence, it should also be taken into account when solving the Schrödinger and Poisson equations. We must calculate the subband energies of the QWs in active region. In our study, this is done by the Finite Difference Method (FDM). A schematic of the SLD structure is shown in Fig. 1. In SLD, the QWs produce the light, while the $\mathrm{SCH}$ and cladding layers play the role of confinement and waveguides of the light, respectively [25]. 


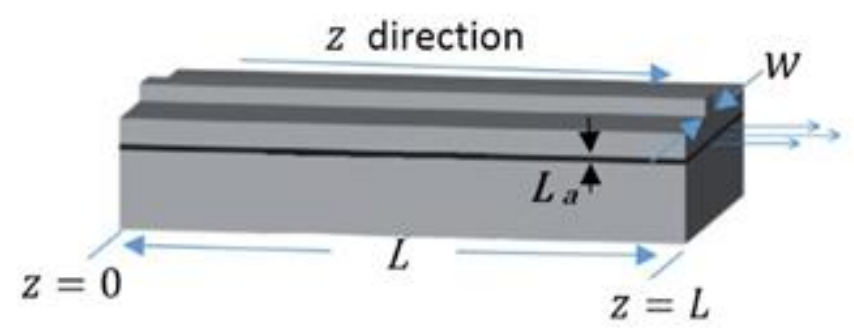

Fig. 1 Schematic of the SLD structure.

Fig. 2 shows the profile of the studied MQW structure in without PZ field (green dashed lines) and with PZ field (blue lines) cases. This structure consists of four $\operatorname{In}_{0.2} \mathrm{Ga}_{0.8} \mathrm{~N}$ QWs (3 nm thickness) separated by three GaN barrier layers (10 $\mathrm{nm}$ thickness). The two AlGaN SCH layers (100 $\mathrm{nm}$ thickness) are located on the up and down of the active region. The temperature of active region is supposed constant $(300 \mathrm{~K})$. The conduction and valence bands of MQW are strongly influenced by the PZ field. The PZ field can change the lineup of conduction and valence bands. Therefore, the depth of the well in the conduction and valence bands increases and decreases, respectively [26]. Also, the PZ field can tilt the structure of the bands. In this case, the structure of the well becomes to a triangular well.

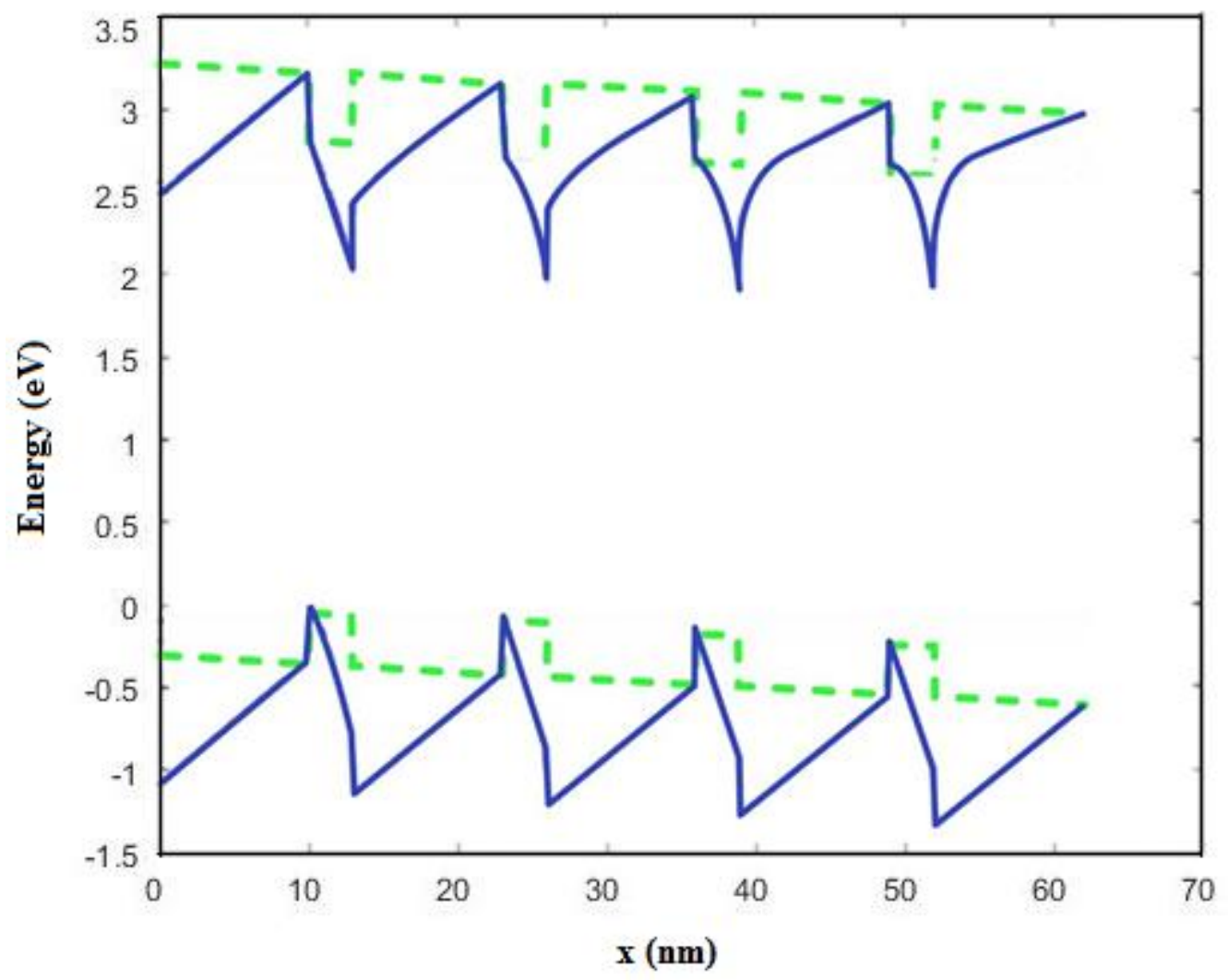

Fig. 2 Profile of the studied structure in without PZ field (green dashed lines) and with PZ field (blue lines) cases. 
In our theoretical model, the rate equations are written by taking into account the effects of carriers escape from MQW to the SCH layer and the transport of carriers from SCH layer to MQW. The optical propagating equations are also written according to spectral power densities, i.e. $P_{ \pm}(z, \lambda)$. We assume that the injection current is applied from the cladding layer to the SCH layer. Therefore, regardless the leakage effect from SCH layer, the equations are

$$
\begin{gathered}
\frac{d N_{S C H}}{d t}=\frac{1}{e} \frac{J}{L_{S C H}}-\frac{N_{S C H}}{\tau_{s}}+\frac{N}{\tau_{e}} \frac{L_{Q W}}{L_{S C H}}-\frac{N_{S C H}}{\tau_{n(S C H)}} \\
\frac{d N}{d t}=\frac{N_{S C H}}{\tau_{s}} \frac{L_{S C H}}{L_{Q W}}-N\left[\frac{1}{\tau_{e}}+\frac{1}{\tau_{n}}\right]-R_{s t} \\
\frac{1}{v_{g}} \frac{\partial P_{ \pm}(z, \lambda)}{\partial t} \pm \frac{\partial P_{ \pm}(z, \lambda)}{\partial z}=[\Gamma g(\lambda)-\alpha] P_{ \pm}(z, \lambda)+\frac{h c}{2 \lambda} \beta \Gamma r_{s p}(\lambda) S
\end{gathered}
$$

In above equations, $J$ is the current density, $N$ is the carrier density per unit volume of QWs, and $N_{S C H}$ is the carrier density per unit volume of the SCH layers. $\tau_{n}$ is the carrier recombination lifetime in the $\mathrm{QW}, \tau_{n(S C H)}$ is the carrier recombination lifetime in $\mathrm{SCH}$ layers, $\tau_{s}$ is the carrier transport time in the SCH layers, and $\tau_{e}$ is the carrier escape time from the well to SCH layer. The relation of $\tau_{s}$ is $\tau_{s}=\tau_{d}+\tau_{c}$, where $\tau_{d}$ and $\tau_{c}$ are diffusion time and capture time, respectively. For MQW active region they are defined as:

$$
\begin{gathered}
\tau_{c}=\Gamma_{q} \tau_{c}^{S Q W} \\
\tau_{d}=\frac{e L_{S C H}^{2}}{2 k T \mu_{n}} \\
\tau_{e}=\frac{\tau_{e}^{S Q W}}{\Gamma_{q}}
\end{gathered}
$$

where $\Gamma_{q}$ is the fraction of the MQW region filled by the QWs. Symbol SQW denotes single QW and $\mu_{n}$ is electron mobility [27-29]. $r_{s p}(\lambda)$ is the spontaneous emission rate of photons [15,30]:

$$
\begin{gathered}
r_{s p}(\lambda)=\frac{8 \pi n_{r}^{2}}{h \lambda^{2}} n_{s p} g(\lambda) \\
n_{s p}=\left[1-\exp \left(\frac{h c \lambda^{-1}-\left(F_{C}-F_{V}\right)}{k T}\right)\right]^{-1}
\end{gathered}
$$

where $F_{C}$ and $F_{V}$ are quasi-Fermi levels in the conduction and valence bands, respectively. $R_{s t}$ is the stimulated recombination of carriers $[15,30]$ :

$$
R_{s t}=\int \Gamma \lambda g(\lambda) \frac{P_{(z, \lambda)}^{+}+P_{(z, \lambda)}^{-}}{h c S} d(\lambda)
$$


and $S$ is the cross section of active region of SLD that defined as multiplication of the thickness and width of the active region. Other parameters are listed in Table 2. The parameters without reference have been calculated for this research and general parameters are available in Ref. [15].

The carrier reduction rates, due to the radiative and non-radiative recombination, are $\tau_{n}^{-1}=A+B N+C N^{2}$ and $\tau_{n(S C H)}^{-1}=A_{S C H}+B_{S C H} N_{S C H}+C_{S C H} N_{S C H}^{2}$, respectively, where $A, B, C$, $A_{S C H}, B_{S C H}$, and $C_{S C H}$ are the Shockley-Read-Hall, spontaneous radiative recombination, and Auger recombination coefficients in QW and SCH layers, respectively [31,32]. We have used the gain in the model of transitions without the k-selection rule because it is better compatible with SLDs [33], therefore by considering this model, the spectral gain as a function of wavelength is expressed by [15]

where

$$
g(\lambda)=G \operatorname{Ln}\left[\frac{1+\exp \left[\frac{\lambda\left(F_{C}-E_{h 1}\right)-h c}{\lambda k T}\right]}{1+\exp \left[\frac{\left(F_{C}-E_{e 1}\right)}{k T}\right]} \times \frac{1+\exp \left[\frac{\lambda\left(F_{V}-E_{e 1}\right)+h c}{\lambda k T}\right]}{1+\exp \left[\frac{\left(F_{V}-E_{h 1}\right)}{k T}\right]}\right]
$$

$$
G=-\frac{2 \lambda e^{2} m_{e w}^{*} m_{h w}^{*} a_{0}^{2} k T}{m_{0}{ }^{2} \varepsilon_{0} n_{r} c^{2} \hbar^{4} \pi L_{Q W}}|M|^{2}
$$

and $n_{r}$ is the refractive index of QW. $E_{h 1}$ and $E_{e 1}$ are the first energy subbands for heavy holes and electrons in QW, respectively. In presence of the PZ field, these values are changed, and therefore the value of gain is changed. $m_{h w}^{*}$ and $m_{e w}^{*}$ are the effective mass of heavy holes in the QW valence band and effective mass of electrons in QW conduction band, respectively [30]. The momentum matrix elements $|M|^{2}$ represent the stimulated electron transitions that depend on the angle between the electron wave vector and the optical field vector. The momentum matrix elements are anisotropic, and the gain depends on the optical polarization. Usually, there are two distinct polarization modes, in which either the electric field (TE mode) or the magnetic field (TM mode) lies within the QW transversal plane (x-y plane) [36-38].

The electric field caused by PZ polarization affects the overlap integral and reduces it. In TE mode, the momentum matrix elements are written as, [15]

$$
\left(M_{T E}^{b}\right)^{2}=\frac{3}{2} O_{i j}\left[\frac{m_{0}}{6}\left(\frac{m_{0}}{m_{e w}^{* t}}-1\right) \frac{E_{g}^{s}\left[\left(E_{g}^{s}+\Delta_{1}+\Delta_{2}\right)\left(E_{g}^{s}+2 \Delta_{2}\right)-2 \Delta_{3}^{2}\right]}{\left(E_{g}^{s}+\Delta_{1}+\Delta_{2}\right)\left(E_{g}^{s}+\Delta_{2}\right)-\Delta_{3}{ }^{2}}\right]
$$

where $O_{i j}$ is the overlap integral, and $m_{e w}^{* t}$ is the electron effective mass in transversal direction relative to the hexagonal c-axis. The $\Delta_{1}, \Delta_{2}$ and $\Delta_{3}$ parameters represent the diagonal and nondiagonal elements of $6 \times 6$ Hamiltonian that explain the three valance bands [35]. The strain changes the band gap energy. In this case, the band gap energy is [24]:

$$
E_{g}^{s}(x)=E_{g}(x)+2 D\left(1-\frac{c_{12}}{c_{11}}\right) \varepsilon_{x x}
$$


where $D$ is the interband hydrostatic deformation potential, and $c_{11}$ and $c_{12}$ are the elastic stiffness constants. Our self-consistent calculations have been carried out in both strained and unstrained cases for comparison.

Table 2 Physical constants and calculated parameters used in this study

\begin{tabular}{|c|c|c|c|c|}
\hline Parameter & Symbol & Unit & Value & Refs. \\
\hline Cavity length & $L$ & $\mu m$ & 800 & \\
\hline Thickness of QW & $L_{Q W}$ & $n m$ & 3 & \\
\hline Thickness of SCH layers & $L_{S C H}$ & $n m$ & 100 & \\
\hline Thickness of active region & $L_{a}=4 L_{Q W}$ & $n m$ & 12 & \\
\hline Width of active region & $w$ & $\mu m$ & 2 & \\
\hline Bohr effective radius & $a_{0}$ & $n m$ & 0.5228 & \\
\hline Lattice constant of $\mathrm{GaN}$ & $a_{\text {GaN }}$ & $A$ & 3.189 & 18 \\
\hline Internal loss coefficient & $\alpha$ & $\mathrm{cm}^{-1}$ & 37 & 34 \\
\hline MQW confinement factor & $\Gamma$ & & 0.017 & 15 \\
\hline Spontaneous coupling coefficient & $\beta$ & & 0.05 & 15 \\
\hline Vacuum permittivity & $\varepsilon_{0}$ & $F m^{-1}$ & $8.85 \times 10^{12}$ & \\
\hline Refractive index of QW & $n_{r}$ & & 3.34 & \\
\hline $\begin{array}{l}\text { Electron effective mass in transversal } \\
\text { direction relative to c-axis in } \mathrm{QW}\end{array}$ & $m^{* t}{ }_{e w}$ & $m_{0}$ & 0.18 & \\
\hline $\begin{array}{l}\text { Effective mass of heavy hole in the QW } \\
\text { valence band }\end{array}$ & $m_{h w}^{*}$ & $m_{0}$ & 0.75 & \\
\hline Shockley-Read-Hall coefficient in QW & $A$ & $s^{-1}$ & $1 \times 10^{7}$ & 31 \\
\hline $\begin{array}{l}\text { Spontaneous radiative recombination } \\
\text { coefficient in } \mathrm{QW}\end{array}$ & $B$ & $C m^{3} s^{-1}$ & $2.0 \times 10^{-11}$ & 31 \\
\hline Auger recombination coefficient in $\mathrm{QW}$ & $C$ & $C m^{6} s^{-1}$ & $1.5 \times 10^{-30}$ & 32 \\
\hline Shockley-Read-Hall coefficient in SCH & $A_{S C H}$ & $s^{-1}$ & $1.2 \times 10^{9}$ & 31 \\
\hline $\begin{array}{l}\text { Spontaneous radiative recombination } \\
\text { coefficient in } \mathrm{SCH}\end{array}$ & $B_{S C H}$ & $C m^{3} s^{-1}$ & $2.4 \times 10^{-11}$ & 34 \\
\hline Auger recombination coefficient in $\mathrm{SCH}$ & $C_{S C H}$ & $C m^{6} s^{-1}$ & $1.4 \times 10^{-31}$ & 32 \\
\hline Escape time in MQW & $\tau_{e}$ & $p s$ & 429.47 & \\
\hline Escape time in single $\mathrm{QW}$ & $\tau_{e}^{S Q W}$ & ps & 122.7 & \\
\hline Transport time in $\mathrm{SCH}$ & $\tau_{s}$ & ps & 1.5736 & \\
\hline Capture time in single $\mathrm{QW}$ & $\tau_{c}^{S Q W}$ & ps & 0.7 & \\
\hline Filling fraction factor in MQW & $\Gamma_{q}$ & & 0.2857 & \\
\hline Crystal-field split energy & $\Delta_{1}=\Delta_{c r}$ & $e V$ & 0.0121 & 35 \\
\hline One-third of spin-orbit split-off energy & $\Delta_{2}=\Delta_{3}=\Delta_{s o} / 3$ & $e V$ & 0.005 & 35 \\
\hline
\end{tabular}


In steady state case, by analyzing the equation (6) and assuming $\exp [\Gamma g(\lambda)-\alpha) L] \succ \succ 1$, the total output power of the SLD in a given current on the right facet of the SLD cavity $(z=L)$ in direct propagation is defined as

$$
\left.P_{\text {out }}=\int \frac{4 \pi \beta S n_{r}^{2} h c^{2} n_{s p}}{\lambda^{5}} \frac{\Gamma g(\lambda)}{\Gamma g(\lambda)-\alpha} \exp [\Gamma g(\lambda)-\alpha) L\right] d \lambda
$$

where $n_{s p}$ is the spontaneous emission factor [15].

By assuming that the $\mathrm{z}$-axis is along the [0001] direction, the Schrödinger equation for electrons and holes is defined as,

$$
\begin{aligned}
-\frac{\hbar^{2}}{2} \frac{\partial}{\partial z}\left[\frac{1}{m_{e}^{*}(z)} \frac{\partial \psi_{e n}(z)}{\partial z}\right]=\left[E_{e n}-V_{C}(z)\right] \psi_{e n}(z) \\
-\frac{\hbar^{2}}{2} \frac{\partial}{\partial z}\left[\frac{1}{m_{h}^{*}(z)} \frac{\partial \psi_{h m}(z)}{\partial z}\right]=\left[E_{h m}-V_{V}(z)\right] \psi_{h m}(z)
\end{aligned}
$$

where $\hbar$ is the planck's constant divided by $2 \pi, m_{e}^{*}(z)$ and $m_{h}^{*}(z)$ are the effective mass of electrons and heavy holes in wells and barriers, respectively, $\psi_{e n}(z)$ and $\psi_{h m}(z)$ are the wave function of electrons and heavy holes in in wells and barriers, respectively. We have neglected light holes and split-off holes because gain spectrum for TE polarization (preferred polarization in SLDs [15]) dominated by the heavy hole band [39]. $E_{e n}$ and $E_{h m}$ are the subband energy of electrons and heavy holes, respectively, and $V_{C}(z)$ and $V_{V}(z)$ are the potential energy in conduction and valance bands, respectively:

$$
\begin{aligned}
& V_{C}(z)=\Delta E_{C}-e F z-e \varphi(z) \\
& V_{V}(z)=\Delta E_{V}+e F z+e \varphi(z)
\end{aligned}
$$

where $\Delta E_{C}$ and $\Delta E_{V}$ are conduction band gap and valance band gap discontinuity, respectively. The Poisson's equation for the electrostatic potential $\phi(z)$ is expressed as follows

$$
\frac{d}{d z}\left[\kappa \varepsilon_{0} \frac{d}{d z} \phi(z)\right]=-e[p(z)-n(z)]
$$

where $n(z)$ and $p(z)$ are electrons and heavy holes distribution for first four levels in the wells and barriers [40]:

$$
\begin{aligned}
& n(z)=\frac{k \operatorname{Tm}_{e}^{*}(z)}{\pi \hbar^{2}} \sum_{n=1}^{4}\left|\psi_{e n}(z)\right|^{2} \operatorname{Ln}\left[1+\exp \left(\frac{F_{c}-E_{e n}}{k T}\right)\right] \\
& p(z)=\frac{k T m_{h}^{*}(z)}{\pi \hbar^{2}} \sum_{m=1}^{4}\left|\psi_{h m}(z)\right|^{2} \operatorname{Ln}\left[1+\exp \left(\frac{E_{h m}-F_{v}}{k T}\right)\right]
\end{aligned}
$$


The process of the simulation method used in this study is presented as flowchart in Fig. 3. As shown, by choosing the minimum current density, and taking into account the initial carrier density and quasi-Fermi Levels equations, the Schrödinger, Poisson and gain equations are solved in the presence of PZ field, and the electronic structure is obtained. Then, the rate equations are solved self-consistently in stationary state. In the case of convergence, the next current density is considered and the program is repeated. Otherwise, the new carrier density is selected and the program is updated. After final current density, the diagrams of the light output power as a function of current, the spectral radiation power as a function of wavelength, and the modal gain as a function of wavelength are plotted.

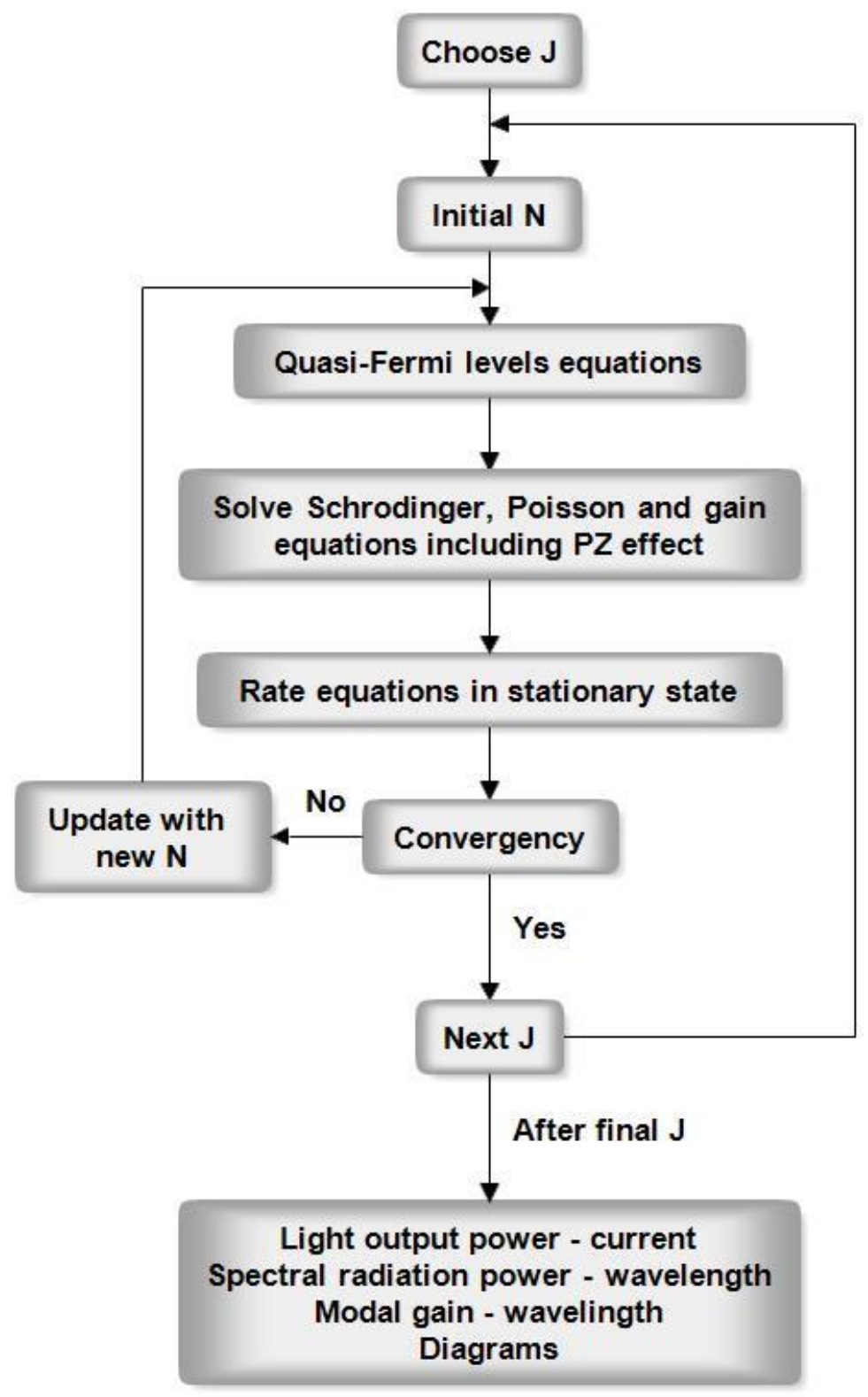

Fig. 3 Flowchart of the process of the simulation method used in this study. 


\section{Results and discussion}

In order to investigate the PZ polarization field effects on the optical properties of the studied device, the light output power as a function of injection current is plotted in Fig. 4 in the cases of with and without PZ polarization. Unlike LDs, the light output power intensity of SLD does not show a sharp threshold, but it gradually rise with increasing of injection current. The soft curvature in the output power curve as a function of the injection current represents the transition from a situation influenced by spontaneous emission (SE) to a situation influenced by ASE. It can be seen from Fig. 4 that with increasing injection current, the output power in both cases (without PZ and with PZ) increases. Comparison of two diagrams shows that in low current injections there are no significant differences in output power of two cases but after that, the output power decreases in the presence of PZ field. The reason for the decline in the output power at high injection currents is that the presence of the PZ field leads to a gradual shrinkage in the spatial overlap between the electron and hole wave functions, where the probability of the radiative recombination diminishes. At applied currents of 110,270 and $540 \mathrm{~mA}$, the differences between the output power in without PZ and with PZ cases are 0.046, 0.136 and $1.081 \mathrm{~mW}$, respectively. At $600 \mathrm{~mA}$ injection current, the maximum powers in without PZ field and with PZ field cases are 13.31 and $11.79 \mathrm{~mW}$, respectively $(8.86 \%$ dropped power).

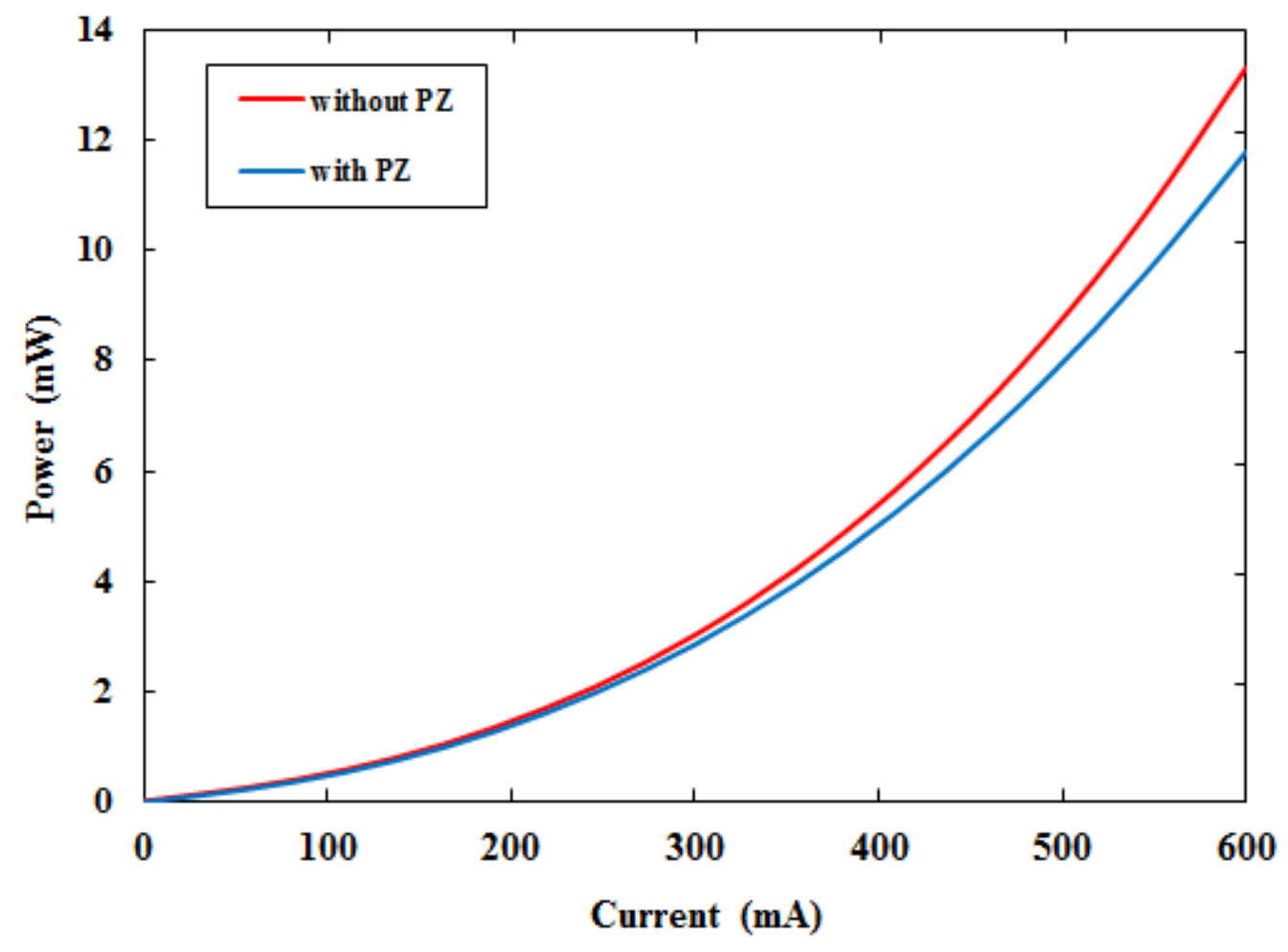

Fig. 4 The light output power as a function of injection current.

Fig. 5 shows the spectral radiation power as a function of wavelength under different injection currents $(400,500$ and $600 \mathrm{~mA})$ in without PZ field and with PZ field cases. According to the 
diagrams, the obtained spectra are in the form of a Gaussian function. The obtained diagrams are in good agreement with the diagram of the experimental work of Tawfik et al. on the LED [41]. The reason for this comparison is that there is no experimental work in this field on SLDs and therefore comparison is not possible. The peak intensity, the width, and the peak wavelength of spectrum in SLD depend on the composition of the active region and the value of injection current. As seen, upon the rise of the injection current, the electroluminescence (EL) spectra show significant luminescence enhancements because of the photo-electric conversion. As can be seen, in both cases (without PZ and with PZ), with increasing the current, the peaks of the spectrum are transmitted to shorter wavelengths. For example, in with PZ field case, as the injection current increased from 400 to $600 \mathrm{~mA}$, the peak wavelength of the spectra shifted from 425.3 to 424.4 $\mathrm{nm}$. This is mainly due to the screening of internal fields [23]. In ternary nitride alloys grown on $\mathrm{GaN}$, similar to the studied structure, the internal fields significantly affect the properties of QW. Upon augmentation of the injection current into the QW, charge screening is expected to reduce the polarization field effects. This effect has a great influence on the band structure and carrier dynamics in QW. The screening of the electric field inside the QW reduces the polarization effects, with this reduction in QW causing improved efficiency of SLD.

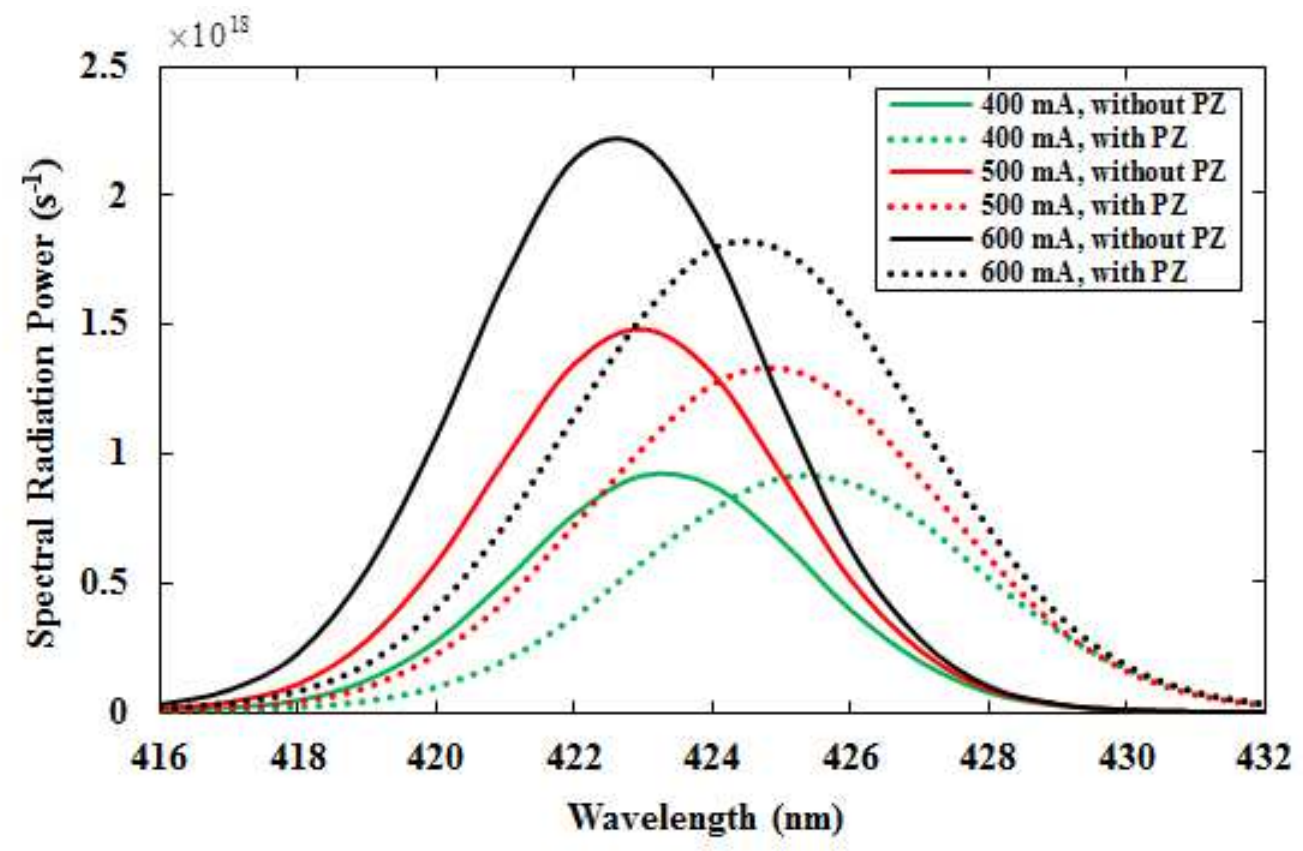

Fig. 5 The spectral radiation power as a function of wavelength under different injection currents in without PZ field and with PZ field cases.

Polarization has an important influence on recombination mechanisms in QWs. The surface polarization charges are somewhat screened by defects of charges, and only about half of them contribute to the internal polarization field [42]. By applying the polarization, the internal field in the p-n junction of the QW is negative, and the holes accumulate at the n-side of junction. In without polarization case, the situation reverses and the holes accumulate on the p-side of the QW. 
In both of the above cases, the electron distribution peak is near the center of the QW. At low injection currents, the spectra are affected by the SE process. By increasing the injection current, the ASE process dominates the spectra thus elevating their bandwidth. This can be clearly seen in Fig. 5. On the other hand, it can be observed that in the presence of the PZ field, the spectra shift toward the higher wavelengths. This phenomenon, so-called the red-shift, attributed to the recombination of carriers at the deep energy levels of QW and to the renormalization of the band gap [41,43].

The useful parameters that are related to the distribution of spectral power density at different wavelengths are the optical bandwidth, the peak wavelength, and the peak intensity of the spectrum. The first parameter is the full width at half maximum (FWHM) of spectral power curve versus wavelength, while the second parameter depends on the wavelength with the highest intensity. Table 3 provides the values of the peak wavelength, FWHM, and the peak intensity of the spectra across different injection currents. It can be observed that in both cases (with PZ field and without PZ field), as the injection current rises, the peak wavelength of the spectra is declined. The PZ field reduces the transition energy in QW, and therefore the red-shift occurs in the emission wavelength.

Table 3 The peak wavelength, FWHM, and the peak intensity of the spectra

\begin{tabular}{c|c|c|c|c|c|c}
\hline \hline \multirow{2}{*}{ current $(\mathrm{mA})$} & \multicolumn{2}{|c|}{ peak wavelength (nm) } & \multicolumn{2}{c|}{ FWHM (nm) } & \multicolumn{2}{c}{ peak intensity $\left(s^{-1}\right)\left[\times 10^{18}\right]$} \\
\cline { 2 - 6 } & without PZ & with PZ & without PZ & with PZ & without PZ & with PZ \\
\hline 400 & 423.3 & 425.3 & 4.9 & 5.9 & 0.926 & 0.921 \\
500 & 422.9 & 424.7 & 5.0 & 5.9 & 1.484 & 1.332 \\
600 & 422.6 & 424.4 & 5.1 & 6.0 & 2.229 & 1.828
\end{tabular}

It can be seen that the PZ field increases the width of the spectrum. The broadening of the spectrum can be attributed to the QCSE and band filling effect $[42,44,45]$. The band filling effect is due to of the occupation of low energy states of bands by the carriers. Consequently, transitions between the occupied states in the valence and conduction bands are prohibited. It should be noted that a strong PZ field, by tilting the band structure in QW, can reduce the effective width of the well and consequently the carrier capture rate in QW. On the other hand, the PZ field, by reducing the overlap of the electron and hole wave functions, prolongs the lifetime of the carriers in the QW. Hence, the probability of carrier escape rate diminishes, and as a result, the peak intensity of the spectra decreases. At injection current of $400 \mathrm{~mA}$, the peak intensity in without PZ field and with PZ field cases are $0.926 \times 10^{18}$ and $0.921 \times 10^{18} s^{-1}$, respectively. At $600 \mathrm{~mA}$, these values are $2.229 \times 10^{18}$ and $1.828 \times 10^{18} s^{-1}$, respectively. It can also be seen that the red-shift occurs in spectra. The results show that in the presence of PZ field, the change in the peak wavelength of the spectra is about $2 \mathrm{~nm}$, which has a good agreement with the results of the Refs. [46] and [47]. At $400 \mathrm{~mA}$, the spectrum peak in cases of with PZ field and without PZ field is in wavelength of 425.3 and $423.3 \mathrm{~nm}$, respectively. At $600 \mathrm{~mA}$, these values are 424.4 and $422.6 \mathrm{~nm}$, respectively.

Fig. 6 shows the FWHM of spectra as a function of injection current in without PZ field and with PZ field cases. In Fig. 5, due to the slight difference in the spectral radiation powers of the 
two cases (with and without PZ) at injection currents of 100 to $300 \mathrm{~mA}$, only the currents of 400 to $600 \mathrm{~mA}$ are considered. In Fig. 6, in order to better compare the FWHM changes in the two cases, the injection currents of 100 to $300 \mathrm{~mA}$ are also considered. As it can be seen from Fig. 6, in the presence of the PZ field, the bandwidth of the spectra increases. The increase of the FWHM of spectra is one of the important features of SLDs. Since the FWHM is dependent on the wavelength and the gain, with increase in the injection current, the gain of device grows, causing enhanced FWHM [11]. In InGaN/GaN MQW structures, the QCSE created by the PZ field separates the electrons and holes spatially. This spreads out the occupancy of the carriers in the joint density of states, whereby the FWHM increases. As previously mentioned, by increasing the injection current, the influence of ASE is intensified, and the spectra are expanded. The maximum value of FWHM in without PZ field obtained in the injection current of $600 \mathrm{~mA}$ is $5.1 \mathrm{~nm}$. In the presence of PZ field, as the current injection increases from 100 to $600 \mathrm{~mA}$, the FWHM values rise from 5.6 to $6.0 \mathrm{~nm}$.

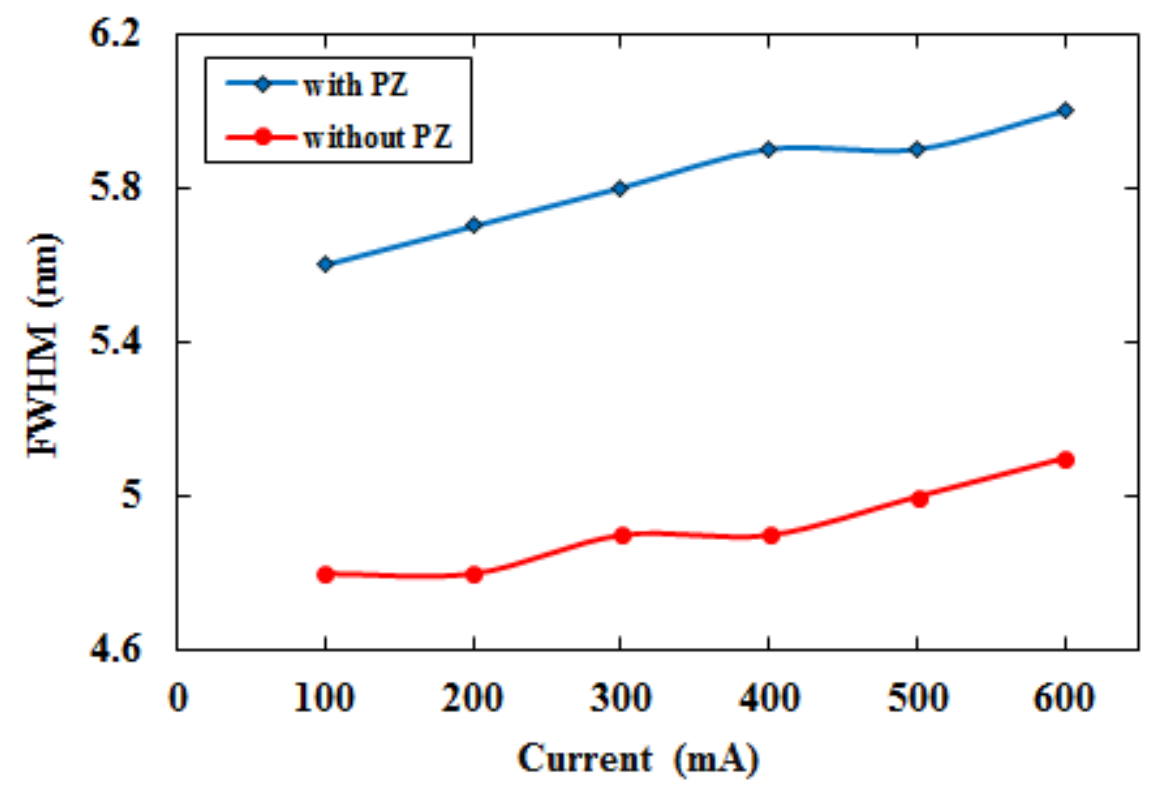

Fig. 6 The FWHM of spectra as a function of injection current in without PZ field and with PZ field cases.

In SLDs, the optical gain is one of the main recombination mechanisms and can be effective on the optical and spectral properties of the structure. Therefore, a careful examination of it is necessary. Fig. 7 shows the modal gain as a function of wavelength in the injection currents of 400, 500 and $600 \mathrm{~mA}$ in without PZ field and with PZ field cases. It is observed that in both cases, with increasing the injection current, the modal gain increases. As the carrier density increases in the active region of the device, the distance between the quasi-Fermi surfaces increases, and thus more surfaces can contribute to the optical gain. As a result, the gain increases. On the other hand, it is observed that the PZ field reduces the gain. This is why in SLDs the internal field caused by the $\mathrm{PZ}$ polarization causes the spatial separation between the electron-hole wave functions. This 
reduces the overlap of electron and hole wave functions and, as a result, the interband optical matrix elements are reduced.

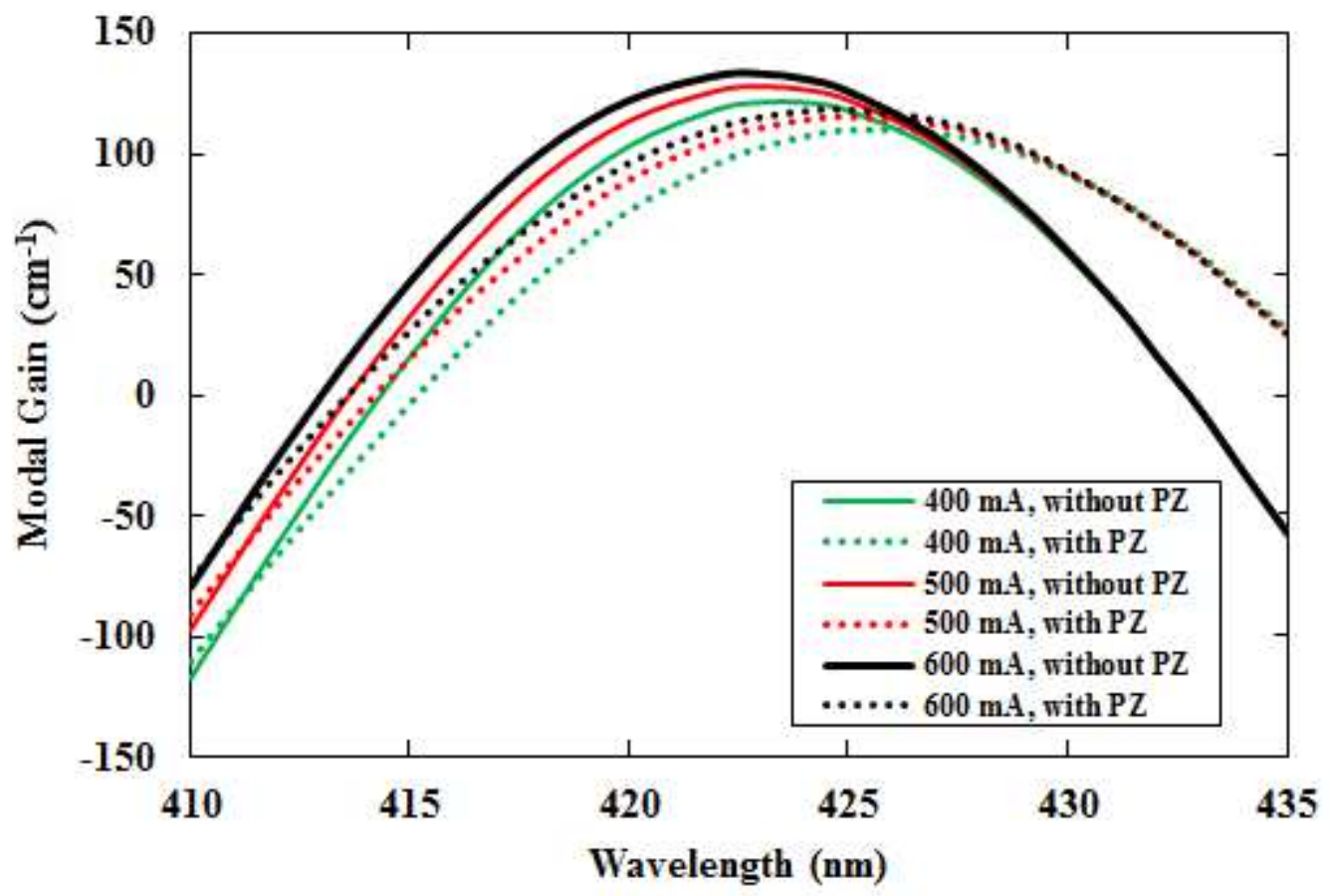

Fig. 7 Modal gain as a function of wavelength at different injection currents in without PZ field and with PZ field cases.

Table 4 presents the peak modal gain values and their corresponding wavelengths at 400, 500 and $600 \mathrm{~mA}$ injection currents in without PZ field and with PZ field cases. As can be seen from the table, by increasing the injection current, the peak modal gain increases in both cases. Also, the position of the gain peaks shifts to shorter wavelengths (blue shift). As the carrier density increases, in addition to the band filling effect, the screening electric field also increases. It can be seen that with increasing injection current from 400 to $600 \mathrm{~mA}$, the blue shift of wavelength in without PZ field and with PZ field cases are 1.0 and $1.1 \mathrm{~nm}$, respectively. On the other hand, it is observed that the PZ field reduces the peak modal gain, and increases the wavelength at which the peak modal gain appears (red shift). These redshift values are 2.1, 2 and $2 \mathrm{~nm}$ in the 400, 500 and $600 \mathrm{~mA}$ injection currents, respectively.

Table 4 The peak modal gain values and corresponding wavelengths

\begin{tabular}{c|c|c|c|c}
\hline \hline \multirow{2}{*}{ current (mA) } & \multicolumn{2}{|c|}{ without PZ } & \multicolumn{2}{c}{ with PZ } \\
\cline { 2 - 4 } & wavelength $(\mathrm{nm})$ & peak modal gain $\left(\mathrm{cm}^{-1}\right)$ & wavelength $(\mathrm{nm})$ & peak modal gain $\left(\mathrm{cm}^{-1}\right)$ \\
\hline 400 & 423.5 & 121.9 & 425.6 & 110.7 \\
500 & 422.9 & 128.1 & 424.9 & 115.1 \\
600 & 422.5 & 133.4 & 424.5 & 118.9
\end{tabular}




\section{Conclusion}

The effects of the strain-induced PZ polarization field investigated on the spectral and power characteristics of $\mathrm{In}_{0.2} \mathrm{Ga} 0.8 \mathrm{~N} / \mathrm{GaN}$ SLD. The calculations were based on the self-consistent solution of the Schrödinger and Poisson equations, the rate equations, and the optical propagating equations. The results showed that the presence of the PZ field in the structure led to lose of the modal gain of the device and the peak intensity of spectrum, red-shift in spectra, and increase the FWHM and the peak wavelength of spectra. In presence of PZ field, under $600 \mathrm{~mA}$ injection current, the output power has dropped $8.86 \%$. The FWHM was also increased from 5.6 to $6.0 \mathrm{~nm}$.

\section{References}

${ }^{1}$ M. Willatzen, B. Lassen, L. C. Lew Yan Voon, R. V. N. Melnik, " Dynamic coupling of piezoelectric effects, spontaneous polarization, and strain in lattice-mismatched semiconductor quantum-well heterostructures," J. Appl. Phys. 100, 024302 (2006).

${ }^{2}$ S.-H Park, "Piezoelectric and Spontaneous Polarization Effects on Many-Body Optical Gain of Wurtzite InGaN/GaN Quantum Well with Arbitrary Crystal Orientation," Jpn. J. Appl. Phys. 42, 5052 (2003).

${ }^{3}$ S. P. Den Baars, D. Feezell, K. Kelchner, S. Pimputkar, Ch. Pan, Ch. Yen, Sh. Tanaka, Y. Zhao, N. Pfaff, R. Farrell, M. Iza, S. Keller, U. Mishra, J. S. Speck, Sh. Nakamura, "Development of gallium-nitride-based light-emitting diodes (LEDs) and laser diodes for energy-efficient lighting and displays," Act. Mat. 61, 945 (2013).

${ }^{4}$ M.-H. Kim, M. F. Schubert, Q. Dai, J. K. Kim, E. F. Schubert, J. Piprek, and Y. Park, "Origin of efficiency droop in GaN-based light-emitting diodes,” Appl. Phys. Lett. 91, 183507 (2007).

${ }^{5}$ Z. Zang, T. Minato, P. Navaretti, Y. Hinokuma, M. Duelk, Ch. Velez, and K. Hamamoto, "High-Power (> $110 \mathrm{~mW}$ ) Superluminescent Diodes by Using Active Multimode Interferometer," IEEE Phot. Tech. Lett. 22, 721 (2010).

${ }^{6}$ D. S. Mamedov, V. V. Prokhorov, and S. D. Yakubovich, "Superbroadband high-power superluminescent diode emitting at $920 \mathrm{~nm}$," Quantum Electron. 33, 471 (2003).

${ }^{7}$ S. Chen, W. Li, Z. Zhang, D. Childs, K. Zhou, J. Orchard, K. Kennedy, M. Hugues, E. Clarke, I. Ross, O. Wada, and R. Hogg, "GaAs based superluminescent light-emitting diodes with 290-nm emission bandwidth by using hybrid quantum well/quantum dot Structures," Nanoscale Research Letters 10, 340 (2015).

${ }^{8}$ N. Matuschek and M. Duelk, "Modeling and simulation of superluminescent light-emitting diodes (SLEDs)," IEEE. J. Selected Topucs in Quantum Electron. 19, 5, 7800307 (2013).

${ }^{9}$ T. H. Ko, D. C. Adler, J. G. Fujimoto, D. Mamedov, V. Prokhorov, V. Shidlovsky, and S. Yakubovich, "Ultrahigh resolution optical coherence tomography imaging with a broadband superluminescent diode light source," Opt. Express 12, 2112 (2004).

${ }^{10}$ G. R. Goldberg, A. Boldin, S. M. L. Andersson, P. Ivanov, N. Ozaki, R. J. E. Taylor, D. T. D. Childs, K. M. Groom, K. L. Kennedy, and R. A. Hogg, "Gallium Nitride Superluminescent Light Emitting Diodes for Optical Coherence Tomography Applications," IEEE Journal of Selected Topics in Quantum Electronics 23, 2000511 (2017).

${ }^{11}$ C. Shen, T. Kh. NG, J. T. Leonard, A. Pourhashemi, SH.I Nakamura, S. P. Denbaars, J. S. Speck, A. Y. Alyamani, M. M. EL-Desouki, AND B. S. Ooi, "High-brightness semipolar (2021) blue InGaN/GaN superluminescent diodes for droop-free solid-state lighting and visible-light communications," Optics Letters 41, 2608 (2016)

${ }^{12}$ A. Kafar, S. Stanczyk, M. Sarzynski, S. Grzanka, J. Goss, G. Targowski, A. Nowakowska-Siwinska, T. Suski, and P. Perlin, "Nitride superluminescent diodes with broadened emission spectrum fabricated using laterally patterned substrate," Optics Express 24, 9673 (2016)

${ }^{13}$ M. T. Hardy, K. M. Kelchner, Y.D. Lin, P. S. Hsu, K. Fujito, H. Ohta, J. S. Speck, S. Nakamura, and S.P. DenBaars, "m-Plane GaN-based blue superluminescent diodes fabricated using selective chemical wetetching," Appl. Phys. Express 2, 121004 (2009).

${ }^{14}$ K. Holc, L. Marona, R. Czernecki, M. Boćkowski, T. Suski, S. Najda, and P. Perlin, "Temperature dependence of superluminescence in InGaN-based superluminescent light emitting diode structures," J. Appl. Phys. 108, 013110 (2010) 
${ }^{15}$ N. Moslehi Milani, V. Mohadesi, and A. Asgari, "A novel theoretical model for broadband blue InGaN/GaN superluminescent light emitting diodes," J. Appl. Phys.117, 054502 (2015).

${ }^{16}$ J. R. Hook, and H.E. Hall, Solid State Physics (Wiley, Berlin, 1993).

${ }^{17}$ O. Mayrock, H. J. Wunsche, and F. Henneberger, "Polarization charge screening and indium surface segregation in (In,Ga)N/GaN single and multiple quantum wells," Phys. Rev. B 62, 16870 (2000).

${ }^{18}$ H. Zhao, R. A. Arif, and N. Tansu, "Design Analysis of Staggered InGaN Quantum Wells Light- Emitting Diodes at 500-540 nm," IEEE J. Selected Topics in Quantum Electronics, 15, 1104 (2009).

${ }^{19}$ E. T. Yu, X. Z. Dang, P. M. Asbeck, S. S. Lau, and G. J. Sullivan, "Spontaneous and piezoelectric polarization effects in III-V nitride heterostructures," J. Vac. Sci. Technol. B 17, 1742 (1999).

${ }^{20}$ I. Vurgaftman, and J. R. Meyer, "Band parameters for nitrogen-containing semiconductors," J. Appl. Phys. 94, 3674 (2003).

${ }^{21}$ A. Polian, M. Grimsditch, and I. Grzegory, "Elastic constants of gallium nitride,” J. Appl. Phys. 79, 3343 (1996).

22 J. Galczak, R. P. Sarzla, and W. Nakwaski, "Spatial separation of recombining carriers within nitride GaN/(AlGa)N quantum wells induced by piezoelectric phenomena," Opt. Elec. Rev.12, 4, 369 (2004).

${ }^{23}$ T. Takeuchi, Sh. Sota, M. Katsuragawa, M. Komori, H. Takeuchi, H. Amano and I. Akasaki, "QuantumConfined Stark Effect due to Piezoelectric Fields in GaInN Strained Quantum Wells," J. Appl. Phys. 97, 382 (1997).

${ }^{24}$ W. J. Fan, S. F. Yoon, M. F. Li, and T. C. Chong, "Investigation of optical gain of GaInNAs/GaAs compressive-strained quantum wells," Physica B 328, 264 (2003).

${ }^{25} \mathrm{P}$. Navaeipour, and A. Asgari, "Numerical analysis of AlGaAs/GaAs multi-quantum well superluminescent diodes," Physica E 63, 272 (2014).

${ }^{26}$ E. F. Schubert, Light-Emitting Diodes, 2nd ed. (Cambridge University Press, New York, 2006).

${ }^{27}$ Gh. Alahyarizadeh, H. Aghajani, H. Mahmodi, R. Rahmani, and Z. Hassan, "Analytical and visual modeling of InGaN/GaN single quantum well laser based on rate equations," Opt. \& Laser Technol. 44, 12 (2012).

${ }^{28} \mathrm{~J}$.-W Lai and C.-F. Lin, "Carrier diffusion effect in tapered semiconductor-laser amplifier," IEEE. J. Quantum Electron. 34, 1247 (1998).

${ }^{29}$ S. Bennett, C. M. Snowden, and S. Iezekiel, "Rate equation modeling of nonlinear dynamics in directly modulated multiple quantum well laser diodes," VLSI DESIGN 8, 355 (1998).

${ }^{30}$ N. Moslehi Milani, and A. Asgari, "The effects of carrier transport phenomena on the spectral and power characteristics of blue superluminescent light emitting diodes," Physica E 69, 165 (2015).

${ }^{31}$ M. Zhang, P. Bhattacharya, J. Singh, and J. Hinckley, "Direct measurement of Auger recombination in In $0.1 \mathrm{Ga} 0.9 \mathrm{~N} / \mathrm{GaN}$ quantum wells and its impact on the efficiency of $\mathrm{In}_{0.1} \mathrm{Ga}_{0.9} \mathrm{~N} / \mathrm{GaN}$ multiple quantum well light emitting diodes," Appl. Phys. Lett. 95, 201108 (2009).

${ }^{32}$ H. Yoshida, M. Kuwabara, Y. Yamashita, K. Uchiyama, and H. Kan, "Radiative and nonradiative recombination in an ultraviolet GaN/AlGaN multiple quantum well laser diode," Appl. Phys. Lett. 96, $211122(2010)$.

${ }^{33}$ O. V. Zhuravleva, V. D. Kurnosov, K. V. Kurnosov, A. V. Lobintsov, V. I. Romantsevich, V. A. Simakov, R. V. Chernov, "Study of the spectral and power characteristics of superluminescent diodes," Quantum Electron. 34, 15 (2004).

${ }^{34}$ G. Muziol, H. Turski, M. Siekacz, M. Sawicka, P. Wolny, P. Perlin, and C. Skierbiszewski, "Determination of gain in AlGaN cladding free nitride laser diodes," Appl. Phys. Lett. 103, 061102 (2013).

${ }^{35}$ S. Ahmada, M.A. Raushana, S. Kumarb, S. Dalelac, M.J. Siddiquia, P.A. Alvi, "Modeling and simulation of GaN based QW LED for UV emission," Optik 158, 1334 (2018).

${ }^{36}$ A. Asgari, S. Dashti, "Optimization of optical gain in AlxGa1-xN/GaN/AlxGa1-xN strained quantum well laser," Optik 123, 1546 (2012).

37 J. Piprek, Semiconductor Optoelectronic Devices, Introduction to Physics and Simulation, (Elsevier Science, USA, 2003).

${ }^{38}$ H. Zhao, R. A. Arif, Y. K. Ee, and N. Tansu, "Self-consistent analysis of strain-compensated InGaN-AlGaN quantum wells for lasers and light emitting diodes," IEEE J. Quantum Electron. 45, 66 (2009).

${ }^{39}$ J. B. Jeon, B. C. Lee, Yu. M. Sirenko, K. W. Kim, and M. A. Littlejohn, "Strain effects on optical gain in wurtzite GaN,” J. Appl. Phys. 82, 386 (1997).

${ }^{40}$ S. -H. Park, and Y. -T. Moon, "Temperature characteristics of spontaneous emission and optical gain in blue InGaN/GaN quantum well structures,” J. Appl. Phys 114, 083107 (2013).

${ }^{41}$ W. Z. Tawfik, G. Y. Hyeon, and J. K. Lee, "Stress-induced piezoelectric field in GaN-based 450-nm lightemitting diodes," J. Appl. Phys. 116, 164503 (2014). 
${ }^{42}$ B. Arnaudov, D. S. Domanevskii, S. Evtimova, Ch. Ivanov, and R. Kakanakov, "Band-filling effect on the light emission spectra of InGaN/GaN quantum wells with highly doped barriers," Microelectronics Journal 40, 346 (2009).

${ }^{43}$ Sh. Nakamura, and Sh. F. Chichibu, Introduction to Nitride Semiconductor Blue Lasers and Light Emitting Diodes (CRC Press, Florida, 2000).

${ }^{44}$ T. Mukai, M. Yamada, and Sh. Nakamura, "Characteristics of InGaN-Based UV/Blue/Green/Amber/Red Light-Emitting Diodes,”Jpn. J. Appl. Phys. 38, 3976 (1999).

${ }^{45}$ C. Lu, L. Wang, J. Lu, R. Li, L. Liu, D. Li, N. Liu, L. Li, W. Cao, W. Yang, W. Chen, W. Du, Ch. Lee, and $\mathrm{X}$. Hu, "Investigation of the electroluminescence spectrum shift of InGaN/GaN multiple quantum well lightemitting diodes under direct and pulsed currents," J. App. Phys. 113, 013102 (2013).

${ }^{46}$ C. K. Wang, Y. Z. Chiou, T. H. Chiang, and T. K. Lin, "Investigation the Effect of Piezoelectric Polarization on GaN-Based LEDs with Different Prestrain Layer by Temperature-Dependent Electroluminescence,'International Journal of Photoenergy 2015, 135321 (2015).

${ }^{47}$ V. Sheremet, N. Gheshlaghi, M. Sozen, M. Elci, N. Sheremet, A. Aydinli, I. Altuntas, K. Ding, V. Avrutin, U, Ozgur, and H. Morkoc, "InGaN stress compensation layers in InGaN/GaN blue LEDs with step graded electron injectors,"Superlattices and Microstructures 116, 253 (2018). 
Figures

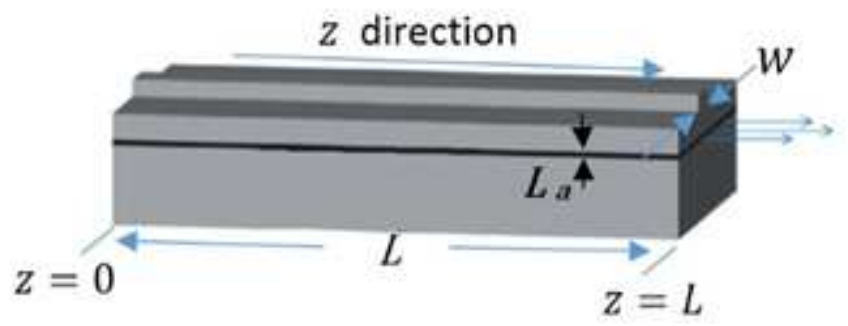

Figure 1

Schematic of the SLD structure.

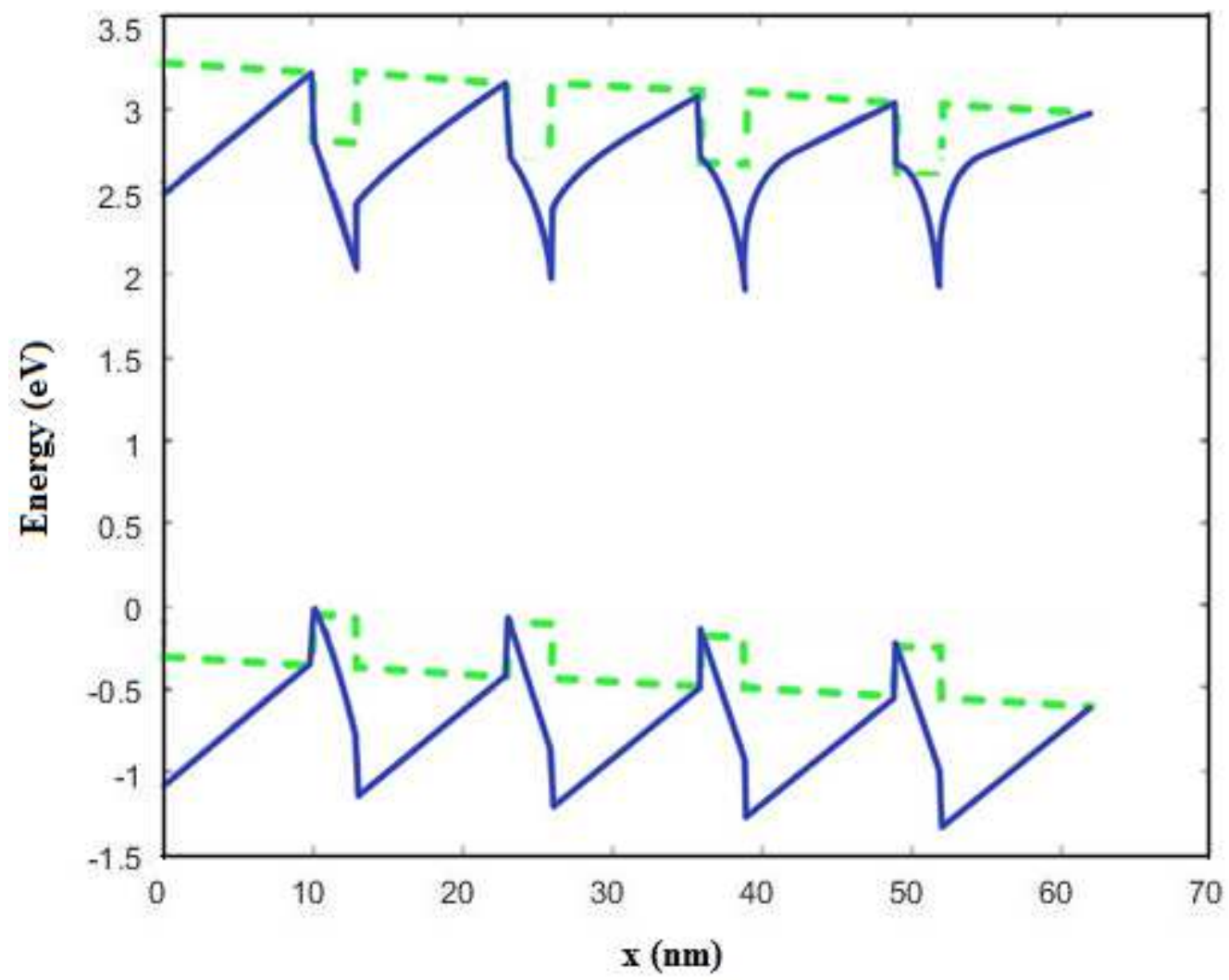

Figure 2

Profile of the studied structure in without PZ field (green dashed lines) and with PZ field (blue lines) cases. 


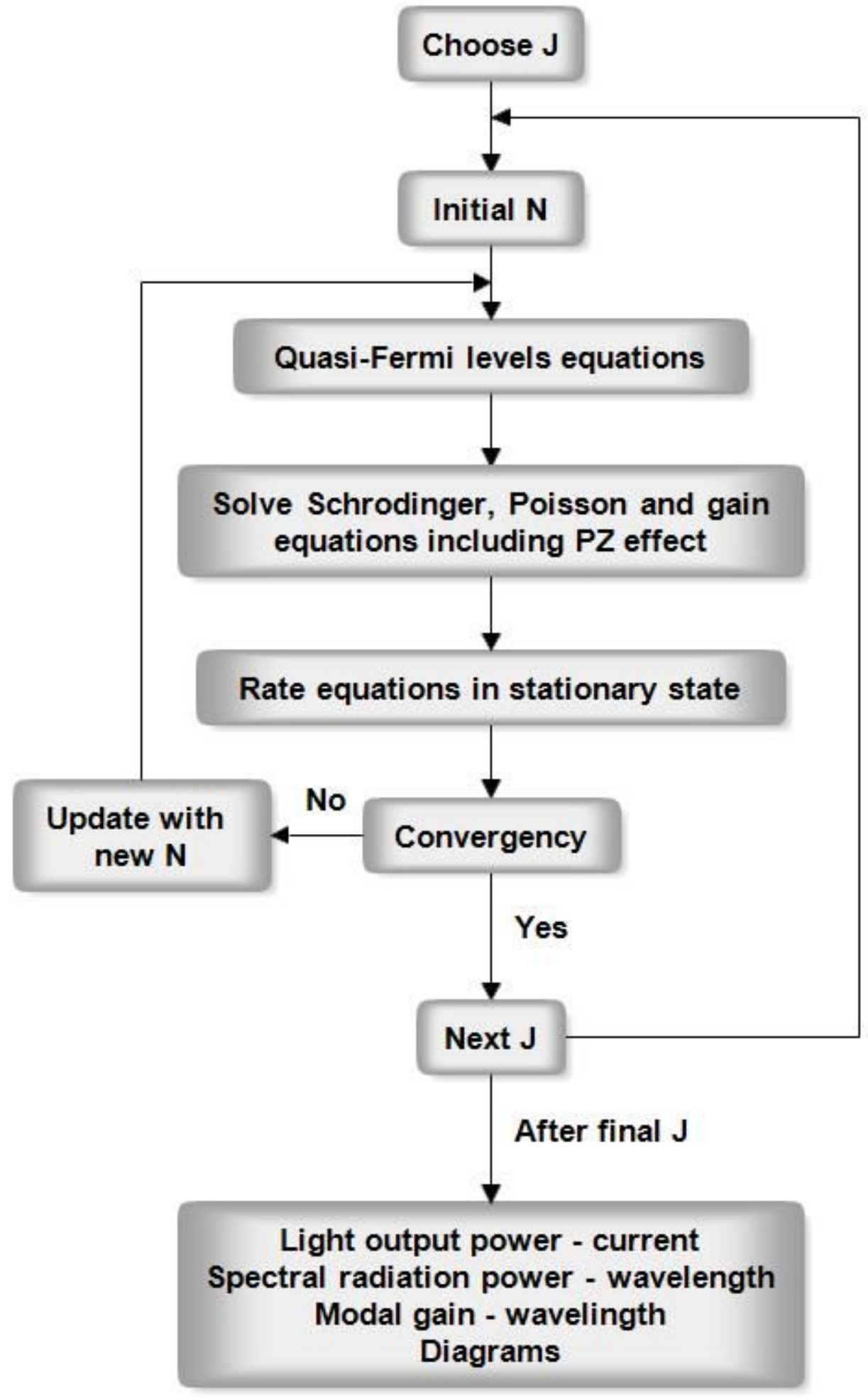

Figure 3

Flowchart of the process of the simulation method used in this study. 


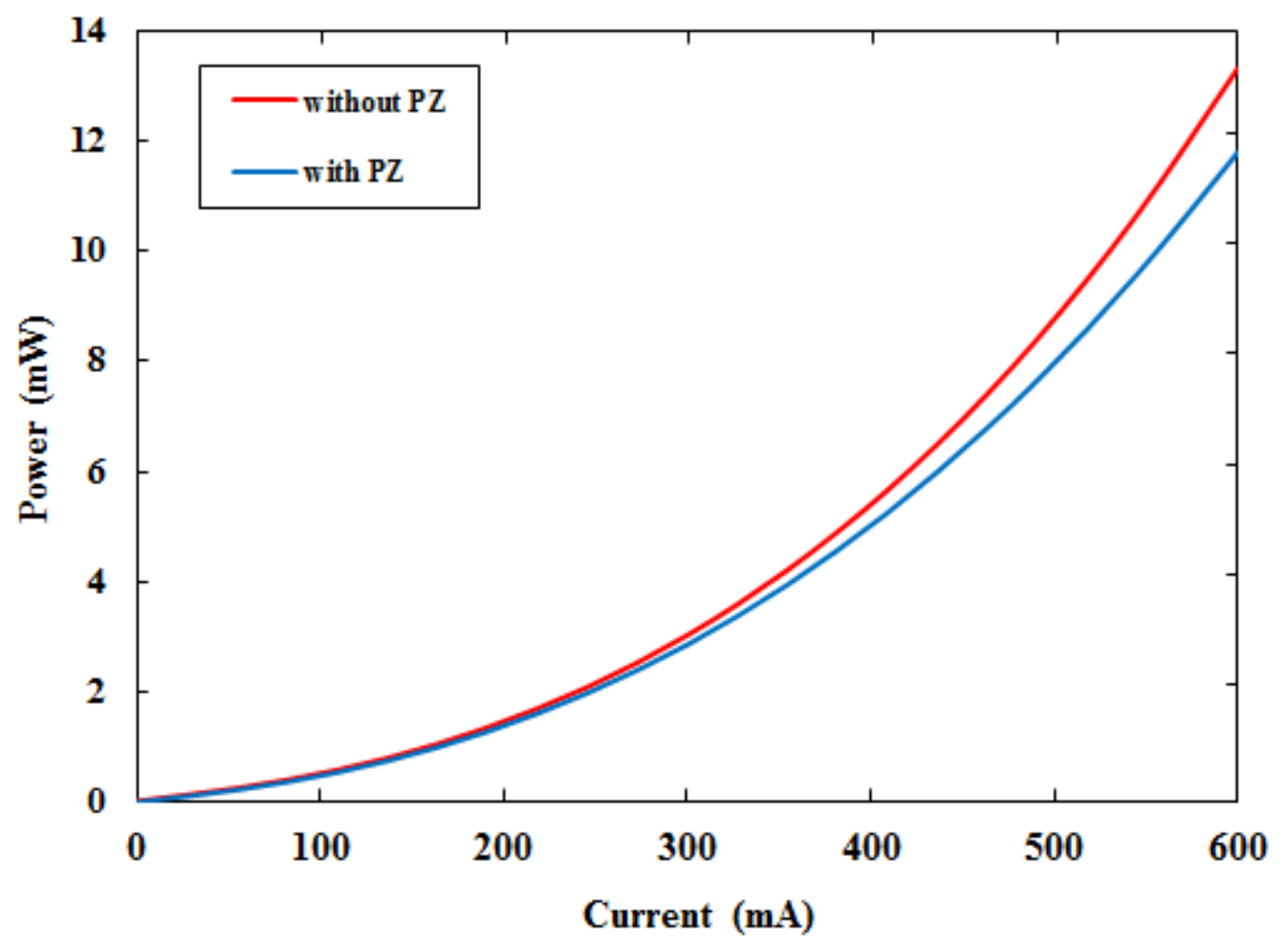

Figure 4

The light output power as a function of injection current.

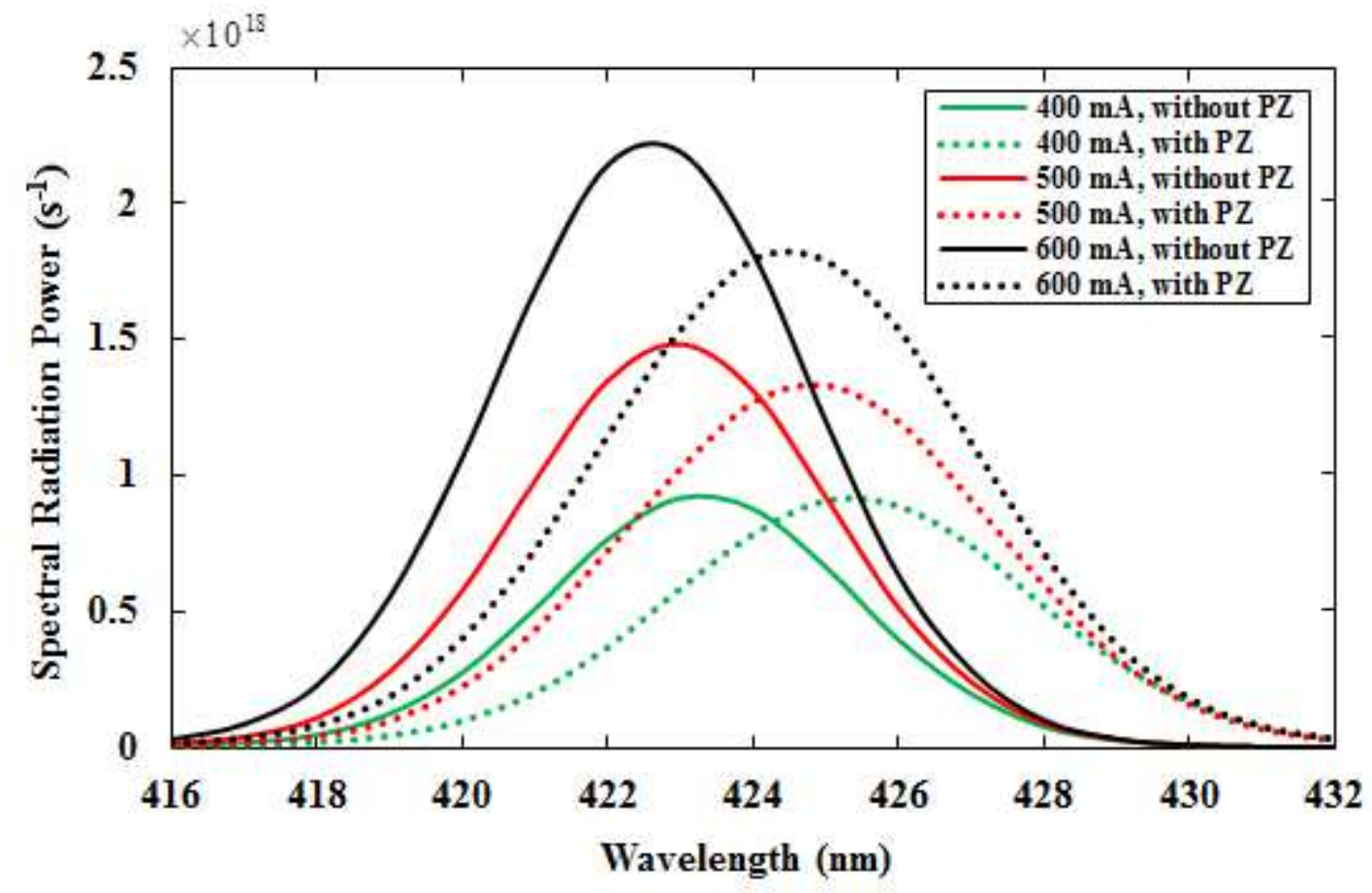

Figure 5

The spectral radiation power as a function of wavelength under different injection currents in without PZ field and with PZ field cases. 


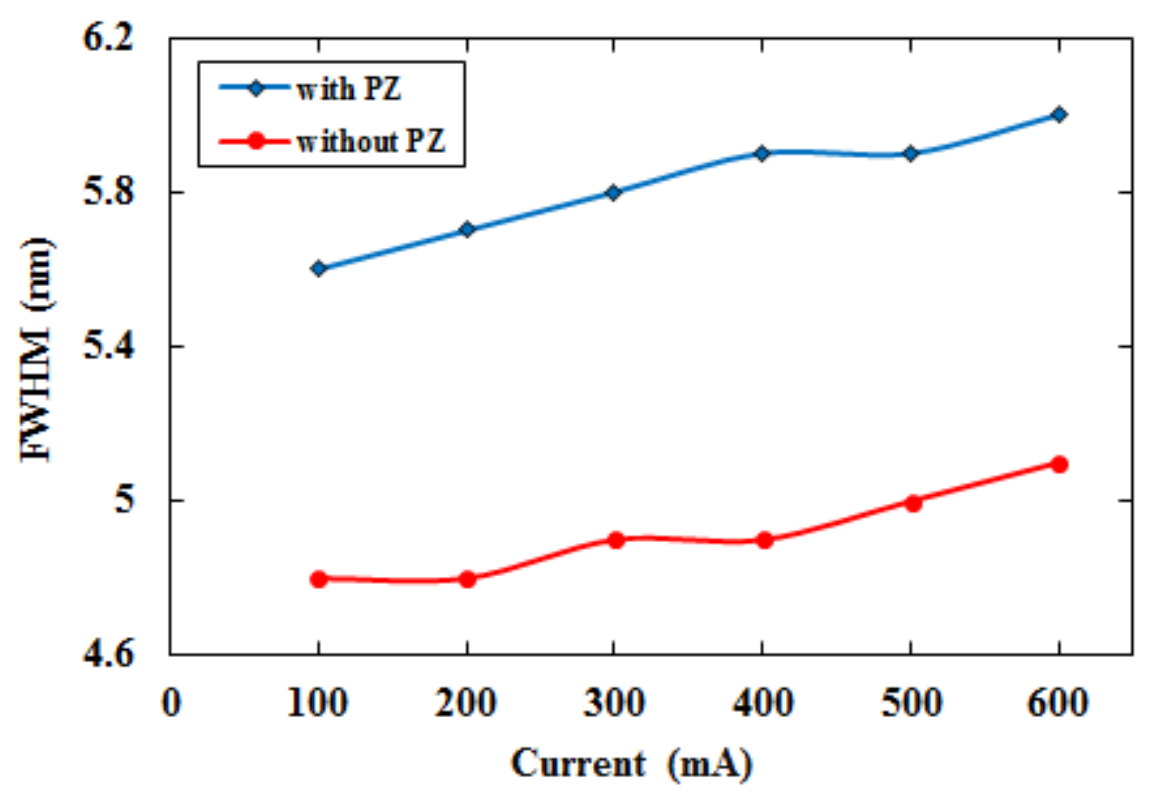

Figure 6

The FWHM of spectra as a function of injection current in without PZ field and with PZ field cases.

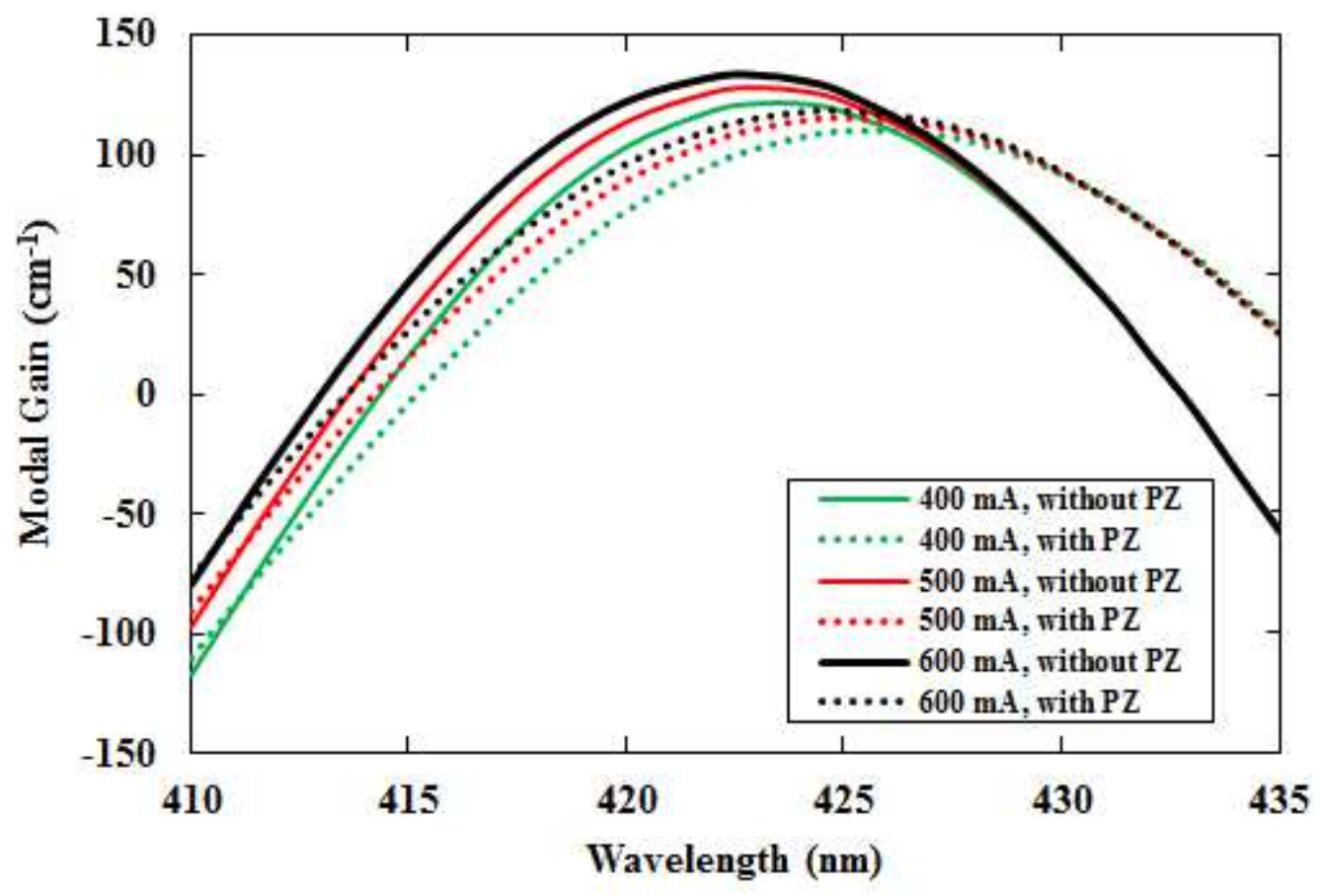

Figure 7

Modal gain as a function of wavelength at different injection currents in without PZ field and with PZ field cases. 